\title{
Transoral versus extraoral approach for mandibular angle fractures: A comparative study
}

\author{
Sathya Kumar Devireddy, R. V. Kishore Kumar, Rajasekhar Gali, Sridhar Reddy Kanubaddy, \\ Mallikarjuna Rao Dasari, Mohammad Akheel \\ Department of Oral and Maxillofacial Surgery, Narayana Dental College \& Hospital, Chintareddypalem, Nellore, \\ Andhra Pradesh, India
}

Address for correspondence: Dr. Mohammad Akheel, Department of Oral and Maxillofacial Surgery, Narayana Dental College and Hospital, Chintareddypalem, Nellore - 524 002, Andhra Pradesh, India. E-mail: akkuthegreatsurgeon@gmail.com

\section{ABSTRACT}

Introduction: Mandibular fractures represent approximately two-thirds of all the maxillofacial fractures (nearly $70 \%$ ) out of which fractures of mandibular angle represent for 26$35 \%$. Aim of the Study: The aim of this study is to compare the transoral and extraoral (submandibular) approaches for fixation of mandibular angle fractures. Objectives of Study: The objectives of the following study are to evaluate ease of accessibility, time taken for the procedure, ease of anatomic reduction and complications. Materials and Methods: A prospective study was carried out in 30 patients reporting to the Department of Oral and Maxillofacial surgery, Narayana Dental College and Hospital, Nellore, Andhra Pradesh during the period of months from November 2011 to August 2013 who were randomly divided in two groups based on computer generated simple randomization chart. Group I patients underwent transoral reduction and fixation and Group II patients underwent extraoral reduction and fixation. The ease of accessibility was analysed by visual analogue scale by the operating surgeon, time taken from incision to closure with digital clock, difficulty level index of surgeon based on the time taken for the procedure and approach related complications. Results: The ease of accessibility in Group I was good in 53.3\% while in Group II patients approached extraorally it was good in $86.7 \%$. Group I patients approached transorally showed a mean of 49.7 min while that of Group II patients approached extraorally showed a mean of 73.4 min. Group I had a minimum difficulty level index in $60 \%$, moderate difficulty level in $33.3 \%$ and severe difficulty level in $6.7 \%$ while Group II had a minimum and moderate difficulty level in $46.7 \%$ and severe difficulty level in $6.7 \%$. There was $1(6.7 \%)$ complication reported in each group. Conclusion: The statistical analysis of this study concludes that fracture line starting anterior to mandibular third molar and ending at anteroinferior border of the insertion of the masseter muscle or posterior body of mandible can be approached transorally. Fracture line starting posterior or distal to the third molar or posterior to the insertion of the masseter muscle to the angle of the mandible or fracture line extending high in the ramus, extraoral approach provides a better choice for reduction and fixation of the fractured

\begin{tabular}{|c|l|}
\hline \multicolumn{2}{|c|}{ Access this article online } \\
\hline Quick Response Code: & Website: \\
\hline & \\
\hline
\end{tabular}
segments with restoration of anatomical and functional occlusion.

\section{KEY WORDS}

Accessibility; difficulty level; extraoral approach; intraoral approach; mandibular angle fractures 


\section{INTRODUCTION}

andibular fractures represents approximately two-thirds of all the maxillofacial fractures (nearly 70\%) out of which fractures of mandibular angle represent for $26-35 \%$ respectively. ${ }^{[1,2]}$ Haug et al. gave the ratio of incidence of mandibular, zygomatic, maxillary fractures was 6:2:1 respectively. ${ }^{[3]}$ There are several reasons proposed for the increased occurrence of mandibular angle fracture: The abrupt change in the anatomy at mandibular angle region which is $20^{\circ}$ in the vertical plane and $90^{\circ}$ in the horizontal plane at the upper border, the presence of impacted mandibular third molars, less cross-sectional area due to the large amount of space occupied by the crypt of mandibular third molars and biomechanical consideration of angle as a lever area of mandible. ${ }^{[4,5]}$ The suprahyoid group of muscles (mylohyoid, geniohyoid, anterior belly of digastric) which are attached to mandible anterior to the angle region exerts a pull inferiorly with the angle acting as a lever area and at the same time muscles of mastication (pterygomassetric sling, temporalis) exert a pull superiorly thereby causing more often but not always displacement of the fractured segments at the angle region. ${ }^{[4]}$ Hence, there is a need for open reduction and internal fixation (ORIF) of mandibular angle fractures.

Decision regarding treatment approaches for ORIF of angle fractures are often dictated to type of fracture, location of fracture, amount of displacement, surgeon's experience and training. Most of the confusion and debate exists about the right approach for fractures of the mandibular angle. There are certain prerequisites for choosing approach: Type of fracture, amount of displacement of fractured segments, number of fractured segments, ease of accessibility and visibility, perfect anatomic reduction of the segments, perpendicular application of drilling device for fixation and approach related complications Hence a prospective study was performed in patients with mandibular angle fractures between transoral and extraoral (submandibular) approach for management of mandibular angle fractures to evaluate ease of accessibility, time taken for the procedure, ease of anatomic reduction and complications.

\section{MATERIALS AND METHODS}

A prospective study was done in 30 patients reporting to the Department of Oral and Maxillofacial surgery,
Narayana Dental College and Hospital, Nellore, Andhra Pradesh from November 2011 to August 2013 who were randomly divided in two groups based on computer generated randomization chart. Group I constituted 15 patients requiring ORIF were approached transorally and Group II constituted 15 patients requiring ORIF were approached extraorally. The inclusion criteria of this study was: Unilateral displaced mandibular angle fractures with deranged occlusion, mandibular angle fractures associated with other maxillofacial injuries and patients with undisplaced angle fractures who were not willing for intermaxillary fixation (IMF). Patients who had fractures of mandibular angle but not willing for open reduction, medically compromised patients who were not fit for general anaesthetic procedures, mandibular angle fractures treated elsewhere before/malunited were excluded from the study. Ethical approval was obtained from Institutional Review Board and a structural informed consent was taken from all patients included in this study.

All eligible patients underwent routine clinical and radiological examination (computed tomography, posteroanterior [PA] view of skull, Orthopantomogram) and haematological examinations of the patients were carried out. Patients underwent pre-operative placement of Erich's arch bars with intermaxillary elastics to facilitate reduction.

\section{Procedure}

Transoral

After administering local anaesthesia, $3 \mathrm{~cm}$ vestibular incision was given distal to $2^{\text {nd }}$ premolar extending to external oblique ridge until the ascending border of ramus [Figure 1]. Mucoperiosteal flap was elevated until the lower border of the mandible and fracture site was exposed and was reduced manually. IMF was placed and then the fracture was fixed with 4 holed $2.5 \mathrm{~mm}$ stainless steel miniplate at the external oblique ridge with $2.5 \mathrm{~mm} \times 8 \mathrm{~mm}$ stainless steel screws [Figure 2]. Closure was done with 3-0 vicryl [Figure 3]. IMF was released before extubation.

\section{Extraoral}

Marking of the incision was done with methylene blue paint. Extraoral submandibular incision of length $5 \mathrm{~cm}$ was placed $2 \mathrm{~cm}$ below the lower border of the mandible in the first neck crease/submandibular shadow [Figures 4 and 5] to have an inconspicuous scar and avoid inadvertent damage to marginal mandibular branch of the facial nerve. A subplatysmal flap was elevated. Facial 
artery and vein were identified and ligated. Dissection of the pterygomassetric sling was done and further dissection exposed the periosteum of inferior border of mandible which was incised thereby exposing the fractured site. IMF was placed. Fracture was reduced and fixed with 4 holed $2.5 \mathrm{~mm}$ stainless steel miniplates on inferior border of angle of mandible and 2 holed $2.5 \mathrm{~mm}$

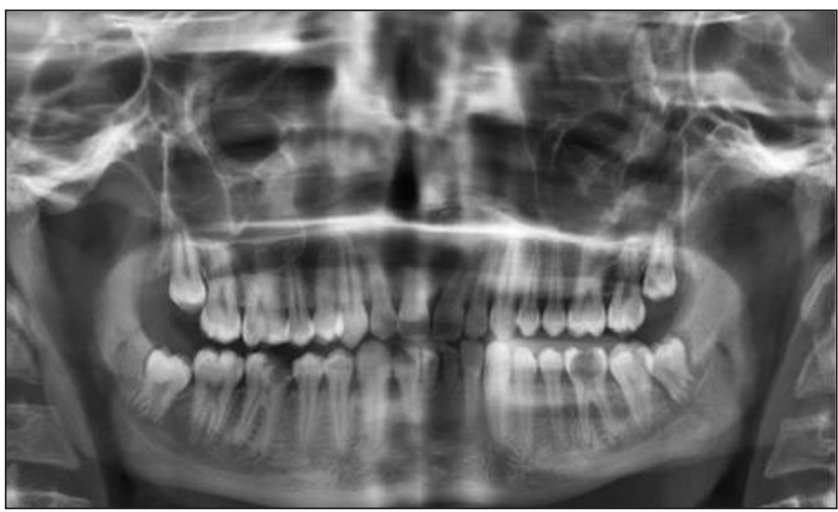

Figure 1: Pre-operative orthopantomogram showing fracture of left angle of mandible

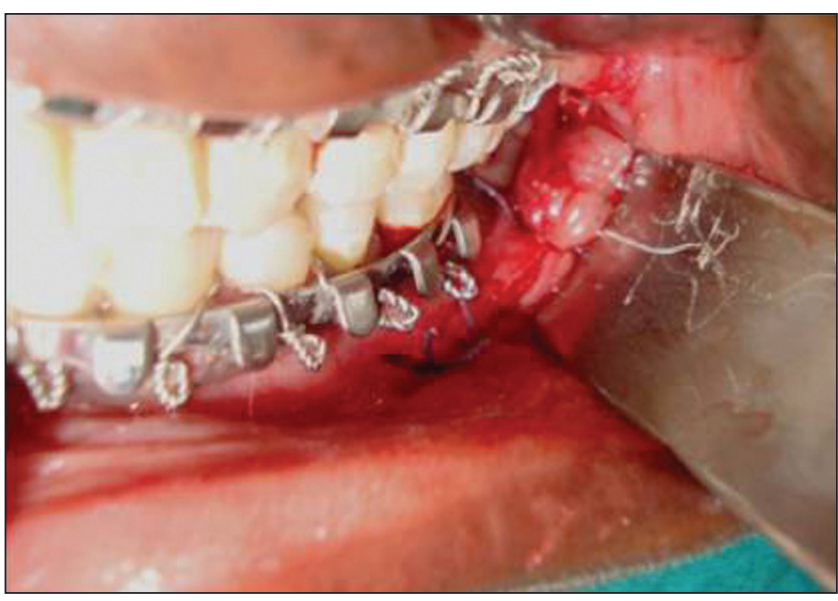

Figure 3: Closure of incision with 2-0 vicryl

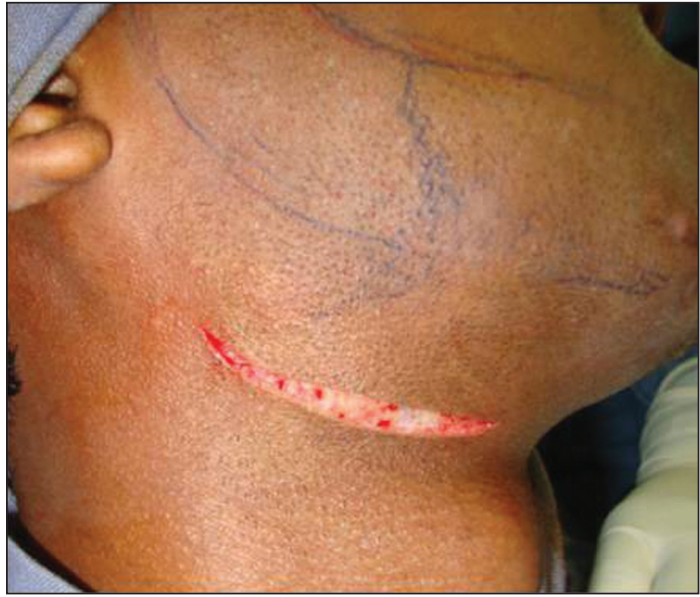

Figure 5: Submandibular incision $2 \mathrm{~cm}$ below lower border of mandible stainless steel plate on superior border of angle of mandible with $2.5 \mathrm{~mm} \times 8 \mathrm{~mm}$ stainless steel screws [Figure 6]. Closure of periosteum, pterygomassetric sling, platysma muscle and subcutaneous tissues were closed

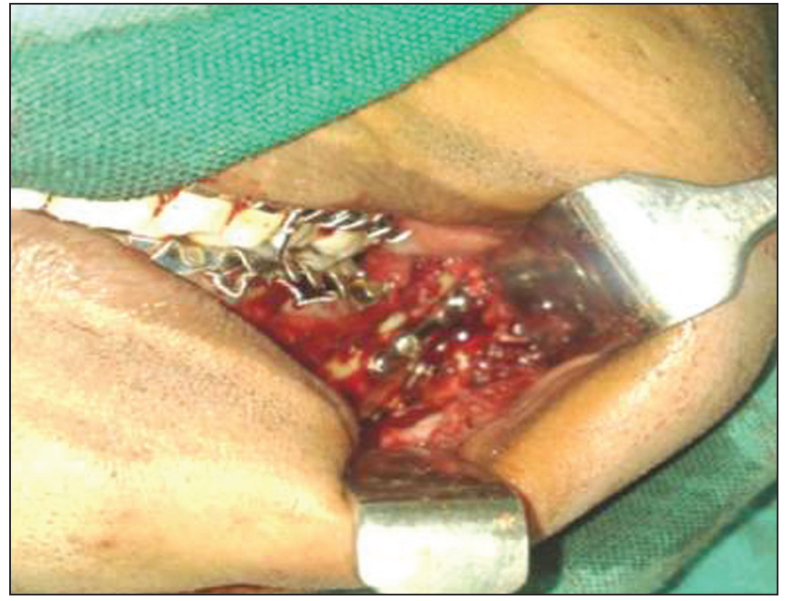

Figure 2: Fixation of fractured segments with 4 holed $2.5 \mathrm{~mm}$ stainless steel plate with $2.5 \times 8 \mathrm{~mm}$ screws at upper and lower border of mandible

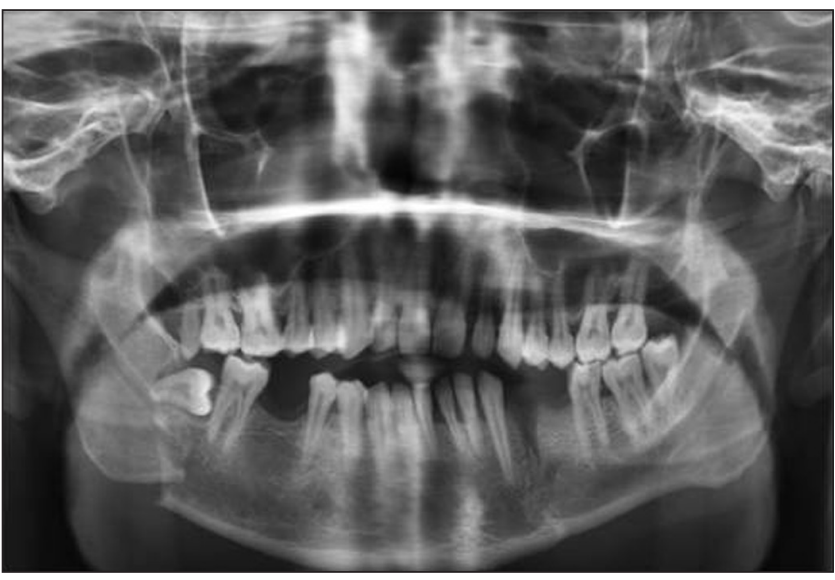

Figure 4: Pre-operative orthopantomogram showing fracture of right angle and left. parasymphysis

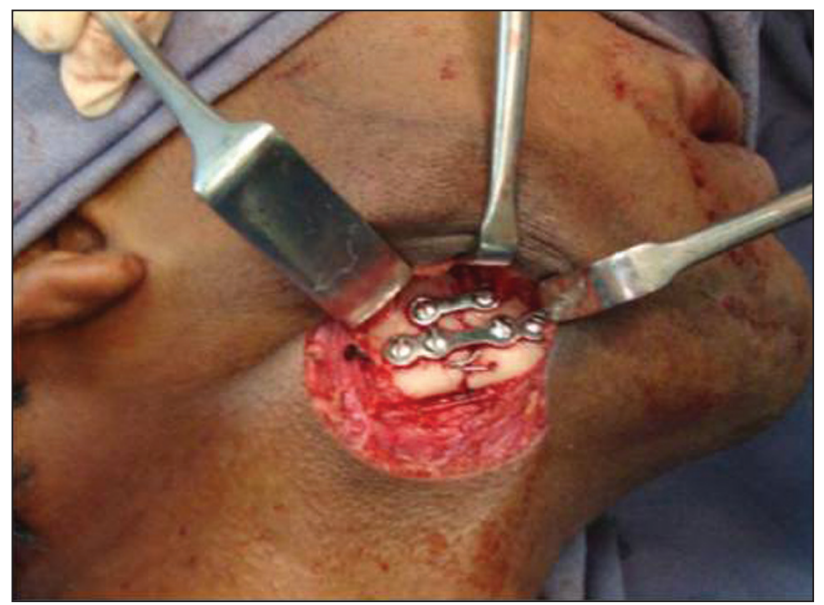

Figure 6: Fixation of fractured segments with 2 holed $2.5 \mathrm{~mm}$ stainless steel plate and 4 holed $2.5 \mathrm{~mm}$ at lower border of mandible with $2.5 \times 8 \mathrm{~mm}$ screws. 
with 3-0 vicryl and skin was closed with subcuticular sutures with 3-0 prolene [Figure 7]. IMF was released before extubation for all patients.

Post-operative oral antibiotics were given for 5 days; panoromic radiographs and PA view of skull were taken for evaluation of the reduction and fixation of the fracture. None of the patients required post-operative IMF in our study due to good anatomic and functional reduction achieved by appropriate approaches. Periodic follow-up of all the patients were carried out until 1 year post-operatively.

All the patients in both groups were performed by 2 maxillofacial surgeons of same maxillofacial unit who had clinical experience of more than 6 years post residency along with 2 final year postgraduate residents. The ease of accessibility was based on visual analogue scale by the operating surgeon and categorized as: No accessibility-0, good- 1 , fair- 2 and poor- 3 . The time taken for the procedure from incision until closure of skin was recorded with same digital clock for all patients. The difficulty level of the procedure was measured by the time taken for the procedure starting from the incision and fixation of fractures and approach related complications were recorded post-operatively. It was divided into three groups based on the time taken: Less than $1 \mathrm{~h}$ - minimum, 1-1.30 h-moderate, greater than $1.30 \mathrm{~h}$ - severe.

\section{RESULTS}

All the patients were clinically evaluated intra-operatively for ease of accessibility, time taken for the incision, exposure till closure of the fracture site, difficulty level for fixation of fractures and complications reported post-operatively.

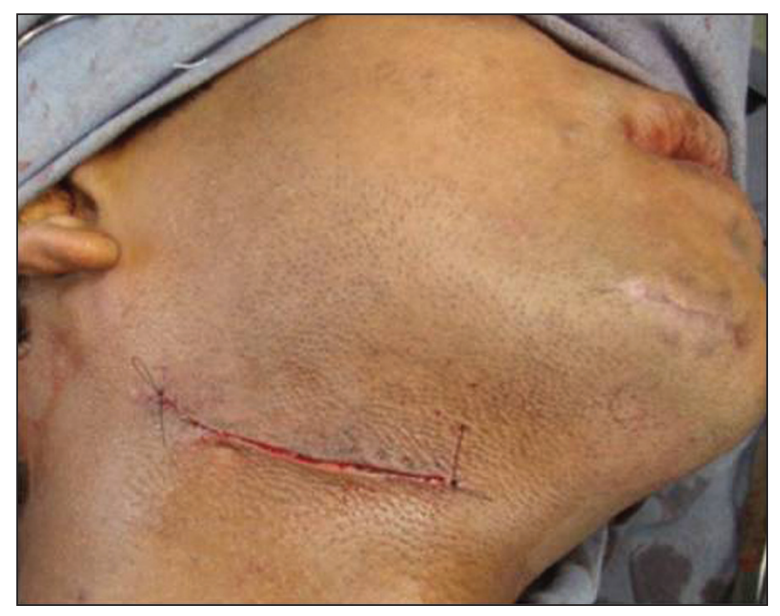

Figure 7: Closure (subcuticular sutures) of skin with 3-0 prolene
The ease of accessibility in Group I patients was good in $53.3 \%$ and fair in $46.7 \%$ while in Group II patients approached extraorally it was good in $86.7 \%$ and fair in 13.3\% [Table 1 and Graph 1]. Hence, extraoral approach provide a better ease of accessibility when compared with transoral approach for a good anatomic reduction and fixation of mandibular angle fractures with screws placed perpendicular to the bone, when compared with transoral approach where the screws are placed obliquely.

The time taken for the surgery which was calculated intraoperatively solely for the management of mandibular angle fractures starting from the placement of the incision (either transorally or extraorally) until the closure of the surgical site. This time was calculated by the same digital clock in both groups. Group I patients approached transorally showed a mean of $49.7 \mathrm{~min}$ while that of Group II patients approached extraorally showed a mean of $73.4 \mathrm{~min}$ [Graph 2]. This difference of $23.7 \mathrm{~min}$ in Group II patients was due to the need for careful dissection of the tissues to reach the fractured site of the mandible and also for the careful aesthetic closure of different layers of the neck and to minimize/avoid post-operative complications.

The difficulty level of both the groups which was calculated based upon the duration of the time recorded. It was divided into three groups: Less than $1 \mathrm{~h}$ - minimum, 1-1.30 h- moderate, greater than 1.30 h- severe. Group I had a minimum difficulty level of $60 \%$, moderate difficulty level of $33.3 \%$ and severe difficulty level of $6.7 \%$. Group II patients had a minimum difficulty level of $46.7 \%$, moderate difficulty level of

Table 1: Accessibility

\begin{tabular}{|c|c|c|c|c|}
\hline \multirow[t]{2}{*}{ Approach } & \multirow[t]{2}{*}{ Sub-parameters } & \multicolumn{2}{|c|}{ ACC_TOA } & \multirow[t]{2}{*}{ Total } \\
\hline & & Fair & Good & \\
\hline \multirow[t]{8}{*}{ ACC_EOA } & Fair & & & \\
\hline & Count & 1 & 1 & 2 \\
\hline & Row (\%) & 50.0 & 50.0 & 100.0 \\
\hline & Column (\%) & 14.3 & 12.5 & 13.3 \\
\hline & Good & & & \\
\hline & Count & 6 & 7 & 13 \\
\hline & Row (\%) & 46.2 & 53.8 & 100.0 \\
\hline & Column (\%) & 85.7 & 87.5 & 86.7 \\
\hline \multirow[t]{3}{*}{ Total } & Count & 7 & 8 & 15 \\
\hline & Row (\%) & 46.7 & 53.3 & 100.0 \\
\hline & Column (\%) & 100.0 & 100.0 & 100.0 \\
\hline \multirow[t]{2}{*}{$\begin{array}{l}\text { Pearson } \\
\text { Chi-square }\end{array}$} & Value & df & $P$ value & $\begin{array}{c}\text { Not } \\
\text { significant }\end{array}$ \\
\hline & 0.01 & 1 & 0.919 & \\
\hline
\end{tabular}

ACC_EOA: Accessibilty-Extraoral approach; ACC_TOA: Acessibility-Transoral approach 
$46.7 \%$ and severe difficulty level of $6.7 \%$ [Table 2 and Graph 3]. Group I had minimum difficulty level in the management of the fractures than the Group II with a difference of $13.3 \%$ and a difference of $13.4 \%$ moderate difficulty level when compared to Group I. This increase

Table 2: Difficulty level index

\begin{tabular}{|c|c|c|c|c|c|}
\hline \multirow[t]{2}{*}{ Approach } & \multirow[t]{2}{*}{ Sub-parameters } & \multicolumn{3}{|c|}{ DL_TOA } & \multirow[t]{2}{*}{ Total } \\
\hline & & Minimum & Moderate & Severe & \\
\hline \multirow[t]{12}{*}{ DL_EOA } & Minimum & & & & \\
\hline & Count & 5 & 2 & 0 & 7 \\
\hline & Row (\%) & 71.4 & 28.6 & 0 & 100.0 \\
\hline & Column (\%) & 55.6 & 40.0 & 0 & 46.7 \\
\hline & Moderate & & & & \\
\hline & Count & 3 & 3 & 1 & 7 \\
\hline & Row (\%) & 42.9 & 42.9 & 14.3 & 100.0 \\
\hline & Column (\%) & 33.3 & 60.0 & 100.0 & 46.7 \\
\hline & Severe & & & & \\
\hline & Count & 1 & 0 & 0 & 1 \\
\hline & Row (\%) & 100.0 & 0 & 0 & 100.0 \\
\hline & Column (\%) & 11.1 & 0 & 0 & 6.7 \\
\hline \multirow[t]{3}{*}{ Total } & Count & 9 & 5 & 1 & 15 \\
\hline & Row (\%) & 60.0 & 33.3 & 6.7 & 100.0 \\
\hline & Column (\%) & 100.0 & 100.0 & 100.0 & 100.0 \\
\hline \multirow{2}{*}{$\begin{array}{l}\text { Pearson } \\
\text { Chi-square }\end{array}$} & Value & df & $P$ value & Not sign & ificant \\
\hline & 2.476 & 4 & 0.649 & & \\
\hline
\end{tabular}

DL_EOA: Difficulty level-Extraoral approach; DL_tOA: Difficulty level- Transoral approach

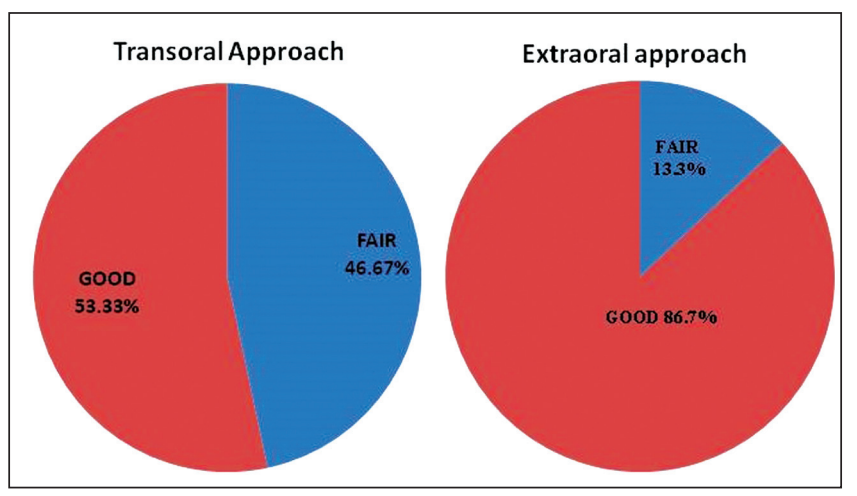

Graph 1: Accessibility

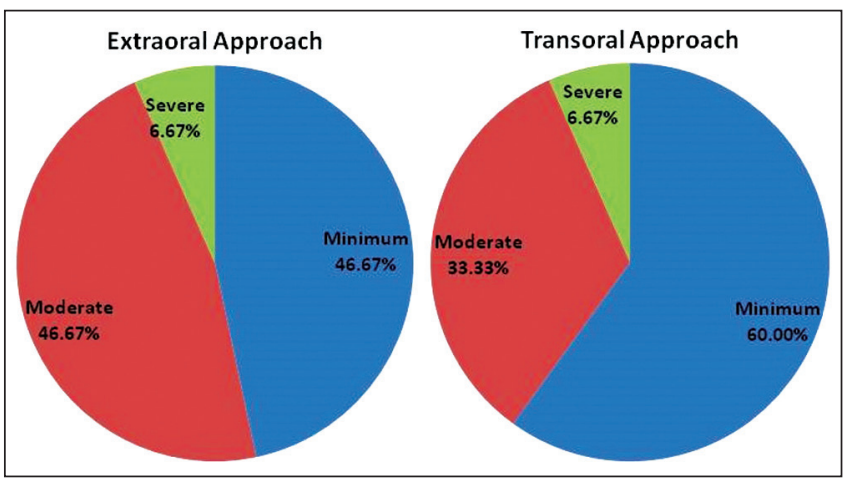

Graph 3: Difficulty level index in difference might be due to careful manipulation of the fractured segments to avoid inadvertent damage to vital structures. In Group II patients there was a slight better chance of obtaining a good anatomic reduction and fixation of the mandibular angle fractures when compared with Group I.

Post-operative complications noted in both groups. In Group I, one patient (6.7\%) had an infection of operated site 3 months following the surgery. Infected plate removal was done under local anaesthesia and post-operative empirical medications were given. The healing of the fractured site and the overlying soft-tissues was uneventful. In Group II patients, one patient $(6.7 \%$ ) had a post-operative transient marginal mandibular nerve weakness on the operated side. There was a complete recovery of the sensation after 6 months. Hence, statistically there was no much of significant complication noted in either of the groups. There was a satisfactory healing of extra oral incision 4 weeks following the surgery and the scar was inconspicuous [Figure 8]. Post-operative follow-up of all the patients were carried out at intervals of 1 month, 3 months, 6 months and 12 months respectively.

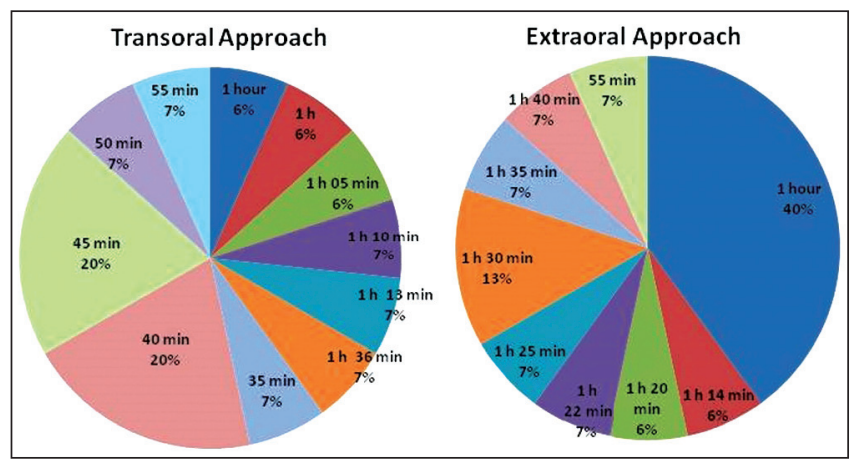

Graph 2: Time taken

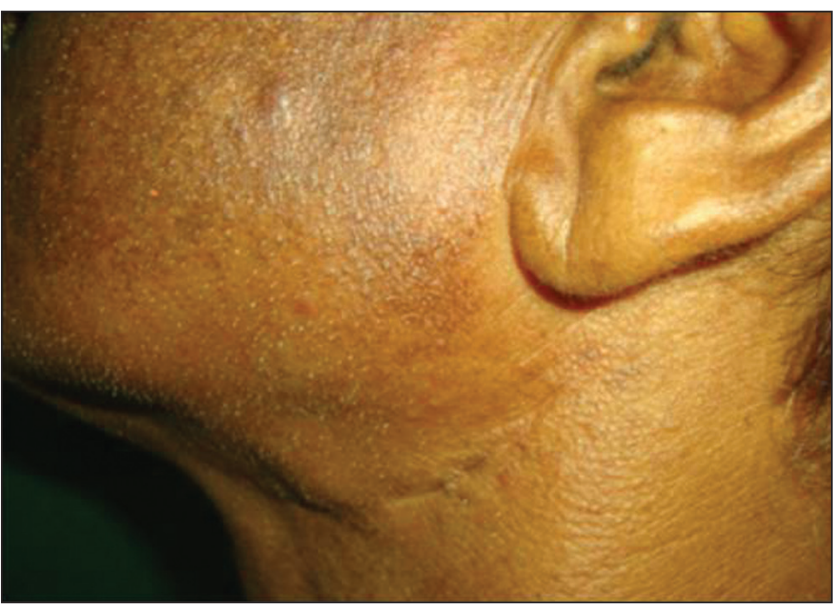

Figure 8: At 3 months post-operative healing of incision 


\section{DISCUSSION}

Mandibular angle fractures are one of the most common types of fractures encountered in the maxillofacial region. Treatment philosophies range from simple maxillomandibular immobilization to rigid internal fixation of bone fragments. ${ }^{|6|}$ Fracture can occur either anterior or posterior to mandibular third molar but rarely involving it. The basic need of rigid internal fixation is primary bone healing under conditions of absolute stability. Rigid internal fixation must neutralize all forces (tension, compression, torsion, shearing) developed during functional loading of the mandible to allow for immediate function. ${ }^{[7]}$ Hamill et al. advocated that successful fixation method depends upon the choice of approach. ${ }^{[8]}$ Extra oral approach was once the most standard traditional and popular approach for management of mandibular angle fractures when compared to transoral approach which was first given by Kazanjian in 1933. Due to the increasing aesthetic demands of the patient and avoidance of extraoral scar, transoral approach has overcome the extraoral approach for the management of mandibular angle fractures ${ }^{[9,10]}$ The main aim of any approach is to promote rapid healing and restore the anatomical form and function with particular care to restablish the functional occlusion and facial aesthetics with minimal disability and complications. A very few studies have been done by Raveh et al., Ellis and Karas, to discuss the differences between transoral and extraoral approaches. ${ }^{[10-14]}$ Decision regarding the approach most often depends upon the anatomical location of the fracture line, type of fracture, amount of displacement of the fractured segments, dentition of the patient, associated maxillofacial fractures and general condition of the patient.

There was an increase in the time taken to expose and fix the fracture site in Group II patients by 23.7 min when compared to Group I patients. This might be due to need for careful extraoral dissection of the tissues, preservation of marginal mandibular nerve, identification and ligation of facial vessels. This was in favour of previous study done by Toma et al. ${ }^{[15]}$ in 2003 who found a difference of $21 \mathrm{~min}$ between transoral and extraoral approach.

The ease of accessibility of the fractured site for visibility and instrumentation was good in $86.7 \%$ in Group II patients than 53.3\% in Group I patients. This provides better chances of good anatomical reduction and control of proximal fragment of the mandible and no iatrogenic damage to the adjacent structures. The advantage of extraoral approach is fixation of 2 miniplates, one at the superior border and one at the inferior border of the mandible to control the tension forces in upper border and compression forces in lower border however certain authors suggest a single superior border plating is enough using transoral approach. ${ }^{[16]}$ Extraoral approach also benefits in providing access for transosseous wiring at the lower border of mandible to assist reduction of the severely displaced fractured segments due to the pterygomassetric pull. ${ }^{[6,17]}$

Difficulty level index was calculated in both the groups based on the time taken for the surgery. There is no much significant difference between both groups. All the patients were operated by 2 maxillofacial surgeons who had more than 6 years of clinical experience in same maxillofacial surgical unit with 2 postgraduate residents. One patient in Group II had a post-operative transient marginal mandibular nerve weakness which was recovered after 6 months following medications. Healing of the incision site in all the patients was good and was inconspicuous in the natural crease of the facial skin. A large incision is much more likely to leave a scar than a small incision but at the same time it must provide a good visualization of the fractured site for reduction and fixation. The deeper and longer the incision, the greater the opportunity for scarring. In our Group II cases, all incisions were 3-4 cm which gave a good exposure for the reduction of fractures. There was no post-operative infection of the extraoral incision or any scar formation in any of our Group II patients and all the incisions healed well with time. Initially all the scars were hard, non-pliable and erythematous, but due course of time they became soft, pale and pliable. Topical application of steroid was given for all Group II (patients). Evaluation of the extraoral skin incision was done on a periodical basis during follow-up of the patient. None of our Group II patients complained for any cosmetic deformity. Post-operative occlusion was satisfactory in all patients with a mean mouth opening of $35 \mathrm{~mm}$ in both groups. Reasons for the post-operative infection of the plate in patient in Group I might be due to improper oral hygiene measures, longer intra-operative time, increased surgical trauma due to excessive manipulation for reduction and fixation of the fractured segments, salivary contamination of the operative field and inadequate postoperative instructions. Empirical antibiotics for compound fractures of the mandibular angle should be instituted as soon as possible after the injury to prevent infection. They should be continued at least until after surgical treatment has been provided. The worth of post-operative antibiotics 
has not been demonstrated. Complication rates of $0 \%$ and $10 \%$ were found by some authors ${ }^{[18]}$ on fractures treated before or after 3 days of the injury. Most of the infections were due transoral approach with or without associated tooth in fracture line irrespective whether it was extracted or retained. ${ }^{[9,19,20]}$ However Moreno et al. ${ }^{[21]}$ advocated that post-operative complication is related to the severity of fracture rather than to the approach of treatment used. Another popular approach is transbuccal which includes both transoral and extraoral stab incision for fixation of mandibular angle fractures. Sugar et al. ${ }^{[22]}$ in 2009 randomly studied 140 patients with mandibular angle fractures to compare fixation with a single mini plate either placed from a combined transbuccal and transoral approach, or intra-orally alone and concluded that transbuccal approach was more preferred by surgeons with the principal reasons being easy to use, minimal requirement to bent fixation in the plate and facilitation of placement of the plate in the neutral mid-point area of the mandible.

Important finding from our prospective study is that fracture line starting anterior to mandibular third molar and ending at anteroinferior border of the insertion of the masseter muscle can be approached transorally as it gives an enough accessibility and visibility for the operating surgeon for the reduction and fixation of the fractured segments with simultaneous control of occlusion, ease of removing the $3^{\text {rd }}$ molar if it is fractured/subluxated or causing an obstruction for the reduction of the fractured segments, less dissection and operating time and minimal oedema due to less manipulation of tissues and minimal healing time. However, the disadvantages include the inability to manage the fractures occurring in the posterior angle region, lack of perpendicular orientation of the drilling device, contamination of the operated site with saliva containing bacteria and food debris if the surgical site doesn't have a water tight closure. However studies done earlier revealed that transoral approach are as stable as extra oral approach and concern over postoperative infections is just unjustified. ${ }^{[10,12,23]}$

If the fracture line is starting posterior to the third molar or fracture line extending high in the ramus, extra oral approach provides a better choice. It provides a sterile environment for the fixation devices, an excellent direct visual exposure, accessibility and control of proximal as well as distal fractured segments for reduction to get an excellent anatomical contour and occlusion of the mandible. It also helps in direct application of fixation devices without difficulty to retract the tissue as seen in transoral approach. ${ }^{[24,25]}$ Some authors proposed that the angle and posterior body fracture have high positive bending moments, small torsion moments and high shear forces and hence need for stability of fixation. ${ }^{[7]}$ This can only be achieved with a good decision of the approach for management of fractures. ${ }^{[26]}$ But simultaneously extraoral approach has a great concern regarding a long cutaneous undesirable scar and also there is an increase likelihood of injury to the branches of marginal mandibular branch of the facial nerve and other associated vital anatomic structures in the hands of inexperienced surgeon and there might be chances of postoperative oedema due to extensive dissection of the tissues with this approach. However from our study we conclude that when compared to the ease of reduction and fixation of fractures and avoidance of residual deformities, extra oral scar is negligible. Achievement of functional and anatomical occlusion is the utmost goal for early rehabilitation of the patient.

\section{CONCLUSION}

The statistical analysis of this study concludes that fracture line starting anterior to mandibular third molar and ending at anteroinferior border of the insertion of the masseter muscle or posterior body of mandible can be approached transorally. Fracture line starting posterior or distal to the third molar or posterior to the insertion of the masseter muscle to the angle of the mandible or fracture line extending high in the ramus, highly unfavourable angle fractures, oblique angle fractures, muscle entrapment between the fractured segments and when there is existing laceration, extra oral approach provides a better choice for reduction and fixation of the fractured segments with restoration of anatomical and functional occlusion.

However as the study sample is less, studies should be done with a large scale of patients to draw definitive conclusions.

\section{REFERENCES}

1. Kuriakose MA, Fardy M, Sirikumara M, Patton DW, Sugar AW. A comparative review of 266 mandibular fractures with internal fixation using rigid (AO/ASIF) plates or mini-plates. $\mathrm{Br} \mathrm{J}$ Oral Maxillofac Surg 1996;34:315-21.

2. Rix L, Stevenson AR, Punnia-Moorthy A. An analysis of 80 cases of mandibular fractures treated with miniplate osteosynthesis. Int J Oral Maxillofac Surg 1991;20:337-41. 
3. Haug RH, Prather J, Indresano AT. An epidemiologic survey of facial fractures and concomitant injuries. J Oral Maxillofac Surg 1990;48:926-32.

4. Fonseca RJ, Walter RV. Oral and Maxillofacial Trauma. $2^{\text {nd }}$ ed., Vol. 1. Pennsylvania: W.B. Saunders Company; 1997. p. 474-8.

5. Leonard PF. Fractures: A History and Iconography of their Treatment. No. 3. Novata CA Norman Publishing; 1990.

6. Ellis $E 3^{\text {rd }}$. Treatment methods for fractures of the mandibular angle. Int J Oral Maxillofac Surg 1999;28:243-52.

7. Tams J, van Loon JP, Rozema FR, Otten E, Bos RR. A threedimensional study of loads across the fracture for different fracture sites of the mandible. Br J Oral Maxillofac Surg 1996;34:400-5.

8. Hamill JP, Owsley JQ Jr, Kauffman RR, Blackfield HM. The treatment of fractures of the mandible. Calif Med 1964;101:184-7.

9. Dierks EJ. Transoral approach to fractures of the mandible. Laryngoscope 1987;97:4-6.

10. Raveh J, Vuillemin T, Lädrach K, Roux M, Sutter F. Plate osteosynthesis of 367 mandibular fractures. The unrestricted indication for the intraoral approach. J Craniomaxillofac Surg 1987; 15:244-53.

11. Ellis $E 3^{\text {rd }}$, Karas $N$. Treatment of mandibular angle fractures using two mini dynamic compression plates. J Oral Maxillofac Surg 1992;50:958-63.

12. Uglesić V, Virag M, Aljinović N, Macan D. Evaluation of mandibular fracture treatment. J Craniomaxillofac Surg 1993;21:251-7.

13. Marciani RD, Anderson GE, Gonty AA. Treatment of mandibular angle fractures: Transoral internal wire fixation. J Oral Maxillofac Surg 1994;52:752-6.

14. Nishioka GJ, Van Sickels JE. Transoral plating of mandibular angle fractures: A technique. Oral Surg Oral Med Oral Pathol 1988;66:531-5.

15. Toma VS, Mathog RH, Toma RS, Meleca RJ. Transoral versus extraoral reduction of mandible fractures: A comparison of complication rates and other factors. Otolaryngol Head Neck Surg 2003;128:215-9.

16. Kimsal J, Baack B, Candelaria L, Khraishi T, Lovald S. Biomechanical analysis of mandibular angle fractures. J Oral Maxillofac Surg 2011;69:3010-4.

17. Choi BH, Kim HJ, Kim MK, Han SG, Huh JY, Kim BY, et al. Management of mandibular angle fractures using the mandibular angle reduction forceps. Int $\mathrm{J}$ Oral Maxillofac Surg 2005;34:257-61.

18. Maloney PL, Welch TB, Doku HC. Early immobilization of mandibular fractures: A retrospective study. J Oral Maxillofac Surg 1991;49:698-702.

19. James RB, Fredrickson C, Kent JN. Prospective study of mandibular fractures. J Oral Surg 1981;39:275-81.

20. Andreasen JO, Storgård Jensen $S$, Kofod $T$, Schwartz $O$, Hillerup S. Open or closed repositioning of mandibular fractures: Is there a difference in healing outcome? A systematic review. Dent Traumatol 2008;24:17-21.

21. Moreno JC, Fernández A, Ortiz JA, Montalvo JJ. Complication rates associated with different treatments for mandibular fractures. J Oral Maxillofac Surg 2000;58:273-80.

22. Sugar AW, Gibbons AJ, Patton DW, Silvester KC, Hodder SC, Gray $\mathrm{M}$, et al. A randomised controlled trial comparing fixation of mandibular angle fractures with a single miniplate placed either transbuccally and intra-orally, or intra-orally alone. Int J Oral Maxillofac Surg 2009;38:241-5.

23. Barry CP, Kearns GJ. Superior border plating technique in the management of isolated mandibular angle fractures: A retrospective study of 50 consecutive patients. J Oral Maxillofac Surg 2007;65:1544-9.

24. Kale TP, Baliga SD, Ahuja N, Kotrashetti SM. A comparative study between transbuccal and extra-oral approaches in treatment of mandibular fractures. J Maxillofac Oral Surg 2010;9:9-12.

25. Pattar P, Shetty S, Degala S. A prospective study on management of mandibular angle fracture. J Maxillofac Oral Surg 2013:1-7.

26. Cobb AR, Walsh S, Lee NJ, Kumar M, Bailey BM. The addition of a locking plate to a modified transbuccal retractor confers increased stability and easier soft tissue control in the application of miniplates in the management of mandibular angle fractures. $\mathrm{Br} J$ Oral Maxillofac Surg 2008;46:247-8.

How to cite this article: Devireddy SK, Kishore Kumar RV, Gali R, Kanubaddy SR, Dasari MR, Akheel M. Transoral versus extraoral approach for mandibular angle fractures: A comparative study. Indian J Plast Surg 2014;47:354-61.

Source of Support: Nil, Conflict of Interest: None declared.

Announcement

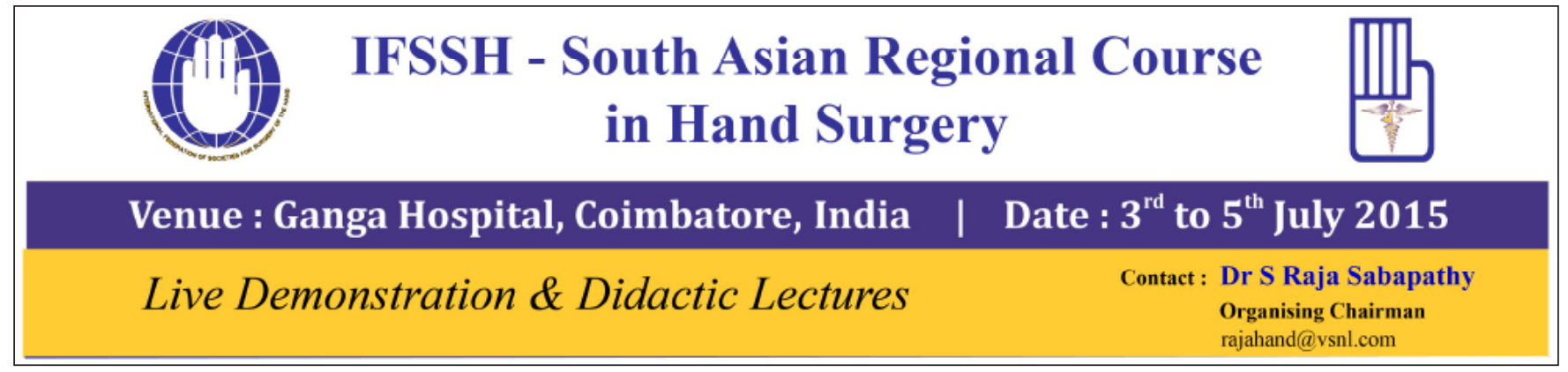

